\title{
Utdanningstilbud i Dialektisk atferdsterapi (DBT)
}

\author{
Ved Anniken Dønvold
}

\begin{abstract}
Nasjonalt senter for selvmordsforskning og -forebygging (NSSF) tilbyr utdanning og kurs i dialektisk atferdsterapi (DBT) i Norge. DBT ble utviklet av den amerikanske psykologen Marsha M. Linehan, University of Washington, Seattle, som en delvis manualbasert behandlingsmetode for voksne kvinner med borderline personlighetsforstyrrelse og et mønster av gjentatt selvskadende atferd.
\end{abstract}

Terapiformen benyttes i dag også ved angst, depresjoner, spiseforstyrrelser og overfor ungdommer med gjentatt selvskadende atferd og emosjonell dysregulering. Flere studier har vist at denne terapiformen reduserer selvdestruktiv atferd og psykisk symptombelastning for mange pasienter, og i betydelig grad bedrer deres evne til å samarbeide om sitt behandlingsopplegg (Linehan et al., 1999; Koons et al., 2001; Verheul et al., 2003). DBT integrerer kunnskap fra atferdsterapi, kognitiv terapi, læringsteori samt dialektisk og фstlig (zen-) filosofi. DBT er en behandlingsform som forutsetter at terapeuter jobber i team.

På oppdrag fra Helsedirektoratet er det igangsatt et treårig utdanningsprosjekt i DBT i Norge. Dette er et samarbeid mellom Nasjonalt senter for selvmordsforskning og -forebygging (NSSF) v/Universitetet i Oslo og Regionsenter for barn og unges psykiske helse (RBUP Øst og S $\varnothing$ r). Utdanningsprosjektet startet opp 1. januar 2008 og vil vare ut 2010. Det er imidlertid planer om å etablere et permanent tilbud om DBT-utdanning her i Norge.

Utdanningsprosjektets målsetting er bl.a. å tilby en utdanning som bidrar til å heve kunnskaps- og ferdighetsnivået i behandling av pasienter med gjentatt villet egenskade, suicidalitet og emosjonell dysregulering. Utdanningen gjennomføres som to intensivsamlinger av en ukes varighet med om lag seks måneders mellomrom. I første intensivuke benyttes forelesninger, video og smågruppe $\varnothing$ velser til grundig læring av DBT-teori og behandlingsstrategier. I perioden mellom intensivukene skal det enkelte DBTteam utforme og implementere sitt eget lokale DBT-behandlingsprogram. I andre intensivuke presenterer hvert team sitt arbeid og får konsultasjon på konkrete kasus. Alle teamene făr regelmessig veiledning underveis i utdanningen, og i seks måneder etterpå.
Da man ikke har godkjente DBT-lærere i Norge, har NSSF og RBUP Øst og Sør inngått et nært og godt samarbeid med Behavioral Tech LLC (BTECH) i USA. BTECH er grunnlagt av Marsha M. Linehan, og har i flere år utdannet DBTterapeuter i USA og Europa. Fra BTECH bidrar Heidi Heard (Ph. D) og Sarah Reynolds (Ph.D), som begge er psykologer, med undervisning og veiledning av utdanningskandidatene/teamene som er under utdanning i Norge. Samtidig har NSSF, i samarbeid med BTECH, under veiledning og utdanning fem norske DBT-lærere, noe som gjør at man i løpet av noen få år kan tilby utdanning i DBT på norsk.

Utdanningstilbudet er så langt blitt godt mottatt i Norge. Utdanningsprosjektet har utdannet to kull med DBTterapeuter, og andre kull var ferdig medium mars 2010. Gjennom disse kullene er det utdannet 64 DBT-terapeuter i 15 nye DBT-team. Det er dessuten foretatt supplering av nye terapeuter i fire eksisterende team. Nytt kull er planlagt med oppstart høsten 2010. Norge er det første landet i Skandinavia som selv har under etablering et regelmessig tilbud om DBTutdanning, kortere kurs etc. I Sverige er BTECH selv inne og tilbyr utdanningen, men med ulik frekvens. I Danmark er man i startfasen ift. planlegging og organisering av et tilbud om DBT-utdanning.

DBT er en terapiform som det tar tid å lære seg fullt ut. Det er mye teori etc. som gjennomgås den første intensivuken, og noen synes det er litt overveldende, spesielt de første undervisningsdagene. Dette stoffet skal man imidlertid modnes med i løpet av de seks neste månedene gjennom utvikling og implementering av teamets eget DBT-program, egne pasienter, veiledning pr. telefon og hjemmelekser. Erfaring viser at det har skjedd en stor utvikling hos den enkelte utdanningskandidat og i teamene når man kommer tilbake til andre intensivuke, som hovedsakelig er klinisk orientert. Evaluering fra utdanningskandidatene våre så langt viser at de er godt fornøyde med utdanningen.

I tillegg til tilbud om DBT-utdanning har man utviklet introduksjonskurs i DBT av ulik varighet. Dette tilbys som klinikkinterne og åpne kurs. Utdanningsprosjektet har videre jobbet med ulike utviklingsoppgaver i forhold til å bygge opp om DBT som terapiform her i Norge.

Anniken D $\phi$ nvold er koordinator for DBTutdanningen i Norge.

\section{Referanser}

Koons, C. R., Robins, C. J., Tweed, J. L., Lynch, T. R., Gonzalez, A. M., Morse, J. Q., Bishop, G. K., Butterfield, M. I., \& Bastian, L. A. (2001). Efficacy of Dialectical Behavior Therapy in Women Veterans with Borderline Personality Disorder. Behavior Therapy, 32, 371-390.

Linehan, M. M., Schmidt, H., Dimeff, L. A., Kanter, J. W., Craft, J. C., Comtois, K. A., \& Recknor, K. L. (1999). Dialectical Behavior Therapy for Patients with Borderline Personality Disorder and Drug-Dependence. American Journal on Addiction, 8, 279-292.

Verheul, R., Van Den Bosch, L. M. C., Koeter, M. W. J., De Ridder, M. A. J. , Stijnen, T., \& Van Den Brink, W. (2003). Dialectical Behaviour Therapy for Women with Borderline Personality Disorder, 12-month, Randomised Clinical Trial in The Netherlands. British Journal of Psychiatry, 182, 135-140.

Utdanning i

Dialektisk atferdsterapi (DBT)

Nytt kull starter høsten 2010
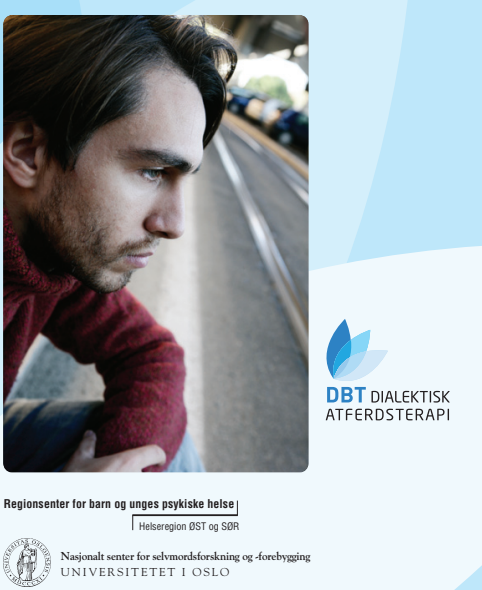